Article

\title{
Dry Bulk Carrier Investment Selection through a Dual Group Decision Fusing Mechanism in the Green Supply Chain
}

\author{
Shuang Yao ${ }^{1, *(\mathbb{D})}$, Donghua Yu ${ }^{2}$, Yan Song ${ }^{3}$, Hao Yao ${ }^{3}$, Yuzhen $\mathrm{Hu}^{3}$ and Benhai Guo ${ }^{1}$ \\ 1 College of Economics and Management, China Jiliang University, Hangzhou 310018, China; \\ guobenhai@163.com \\ 2 School of Computer Science and Technology, Harbin Institute of Technology, Harbin 150001, China; \\ donghuayu@hit.edu.cn \\ 3 College of Economics and Management, Harbin Engineering University, Harbin 150001, China; \\ tigersy@163.com (Y.S.); yaohao@blue-soul.cn (H.Y.); yuzhenhu@hrbeu.edu.cn (Y.H.) \\ * Correspondence: alloniam@163.com; Tel.: +86-155-5803-7525
}

Received: 29 October 2018; Accepted: 27 November 2018; Published: 30 November 2018

\begin{abstract}
Uncertain linguistic variables and scoring evaluations are two important evaluation mechanisms in the decision making field. Sustainability requirements for ship investment lead to the complexity of influence factors and the decision making process. The uncertain linguistic assessment features a large amount of ambiguity and subjectivity, while the scoring evaluation features high precision and distinct gradations. This paper constructs a criteria system in the green supply chain and proposes a dual group decision fusing mechanism for integrating the linguistic variable and scoring evaluation into a unified evaluation term. A hierarchical cloud of linguistic variable terms is constructed based on scoring via a reverse cloud generator, and then, the ship investment linguistic terms are transformed into prospect values. In addition, the consistency and investment selection performance are measured after aggregating the individual decision matrices for group decision making. The empirical research results on the selection of dry bulk carriers for investment show that dual group decision fusing mechanisms could effectively improve the consistency, decision making efficiency, and accuracy of dry bulk ship investment choices and reduce the cost of feedback adjustment for group decisions. In comparison with the trapezoidal fuzzy and fuzzy TOPSIS methods of group decision making, the proposed method performs better when there are a large number of alternatives.
\end{abstract}

Keywords: group decision; green supply chain; cloud model; prospect theory; fusion mechanism

\section{Introduction}

Due to the increasing tendency of societies to work toward a sustainable future, every decision, especially for firms related to the national economy, is determined by balancing economic goals with social-ecological concerns [1]. Suppliers, focal companies, and customers are linked by information, material, and capital flows. Along with the value of a product comes its environmental and social burden. In this context, focal companies in supply chains make investment selections and may be held responsible for the environmental and social performance of these selections. Fan [2] empirically analyzed the relationship between ship investment and decision making behavior; he found that shipowners are inclined toward large ship sizes. Most expansion decisions are found to be market-driven, and large companies expand to maintain their market shares and achieve sustainable competitive advantages. According to international conventions along with standard, local, and industrial regulations, green intelligent ships with low emissions, low fuel consumption, 
energy-saving mechanisms, and environmental safeguards are an inevitable trend in the development of the shipbuilding industry. The study of ship investment in the green supply chain benefits from the theory of decision making. The problem of selecting the optimal dry bulk carrier problem in decision theory (DT) depends on green supply chain management (GSCM). A successful GSCM evaluation may include green practice, green policy, green performance, and green collaboration [3]. However, there are challenges involved in successful GSCM, including the uncertainty, complexity, and cost of the objective factors along with the cognitive preferences, value judgments, and attitudes involved in the subjective aspects [4].

Investment selection under the green supply chain is a complex issue with a variety of influencing factors, which can be classified into internal capabilities and external environmental impacts of enterprises. From the internal capabilities, Azimifard [1] introduced the social criterion to the issue of sustainable supplier selection in the steel industry and proposed a sustainability indicators evaluation criterion that includes economic, social, and environmental aspects. The results show that the distance from supplier country to the destination country is obtained as the most important standard weight through empirical research, and Iran is rated as the most sustainable supplier. Sivakumar [5] proposed a model framework and case study involving benefit and risk factors, including green technology capability, R\&D capability, environmental training, and environmental activity control. A green vendor selection framework based on the outsourcing perspective presents an integrated approach of AHPand the Taguchi loss function to help the managers in the mining industry to develop green vendors. Operating the supply chain is only justified if the products and services are ultimately "accepted" by customers [3]. Green cooperation and collaboration play an important role in the overall supply chain performance. Rostamzadeh et al. [6] indicated that the main criteria involved in green supplier selection are as follows: eco-design, green production, green purchasing, green recycling, green transportation, and green warehousing. Then, they proposed an integration of various criteria based on a literature review and illustrated the case of a laptop manufacturer in Malaysia aiming to solve the green multi-criteria decision making problem from practitioners. Sawik et al. [7] analyzed the vehicle routing problems with environmental costs composed of noise, pollution, and fuel consumption. The researchers investigated Spanish grocery companies aiming at the minimum cost, noise, pollution, and fuel consumption. The authors also discussed green vehicle routing problems for optimal fleet size under required transportation tasks' capacity [8]. This provides a mixed-integer programming formulation of multi-criteria vehicle routing problems to find a suboptimal solution of fleet size and total capacity. Gallo [9] proposed a car pricing policy based on fuel surcharges as a substitution of car ownership taxes for reducing greenhouse gas emissions. Based on the GHG emissions estimated for Italy, the results show that car users prefer to shift towards more fuel-efficient vehicles than to public transport, which reduces GHG emissions less than expected. Ngo et al. [10] assessed the causal relationship between an urban greenway, motorized travel behavior, and environment outcomes with the first quasi-experimental and longitudinal cohort study. It is the intention of this study to help guide decision making for transportation investments towards climate change mitigation. The findings help to understand the government strategies pursued to achieve environmental sustainability goals and meet emission reduction targets in the transportation sector.

Multiple criteria decision making (MCDM) is an important part of modern decision science [11,12]. The tools of decision making include individual and group decisions. Group decision makers (DMs) from a variety of fields generate different cognitive information when they evaluate alternatives on the same criterion. Thus, there are many studies on the appropriate and correct expression and computation of cognitive information. As one of the four leading disciplines in decision theory, cognitive science contributes an important perspective in the report "Aggregate of four technical forces promoting the common development of mankind" [13]. In real life, decision makers (DMs) rely on cognition to make decisions. Differences in the cognitive abilities of DMs generate various evaluations for the same criterion on multiple alternatives [14]. The knowledge or cognitive information expression 
for each attribute, which is able to reveal microscopic regularities in the descriptions of attribute characteristics, provides an intelligent support for attribute-based cognition [15].

Owing to the fuzziness and complexity of decision making problems, cognitive information can be represented in various ways. The linguistic term is a prevalent means of expression [16]. The theory of probabilistic linguistic term sets is very useful in objectively dealing with multiple criteria group making problems; the method allows DMs to express their preferences on linguistic terms for the same attributes [17]. DMs tend to express their opinions with fuzziness and ambiguity, as decision problems are always complicated in uncertain environments [18], resulting in human behavioral, psychological, and cognitive impacts on the decision. For example, this information can be represented through linguistic two-tuples [19,20], interval-valued rough random variables [17], or hesitant fuzzy linguistic terms $[18,21]$. In addition, regret theory has an important role in decision theory, such as in the dynamic location problem [22], enterprise production, and marketing strategy [23].

Fuzzy numbers, derived from fuzzy set theory, have become a major method in handling uncertain attributes [24,25]. Cloud model theory is an innovation and development of the membership function in fuzzy set theory [26]. A cloud model transforms the ambiguity and uncertainty of qualitative natural language into quantitative membership values [27] and has been successfully applied to MCDM [28]. Although fuzzy numbers have more freedom to express the complex, uncertain information in real decision making processes, it is still difficult to express the cognitive information of attributes precisely with crisp numbers.

Fusing the cognitive information and reducing the information loss in the decision making process have been two of the most important issues in the computation of cognitive information. In many complex decision making situations, more elaborate and complex linguistic expressions are required to express preferences under a dynamic and high degree of uncertainty. It would be very helpful if the complex linguistic expressions could be manipulated and simplified in the framework of linguistic decision making [29]. Cabreziro et al. [30] suggests linguistic information as a multiobjective optimization task involving a weighted average criterion for consistency. Linguistic terms can be transformed by mapping. Liu and Zhang [14] extended intuitionistic fuzzy sets to fuzzy sets with linguistic terms, developing Archimedean t-norms and s-norms to create a fuzzy linguistic weighted averaging operator to deal with multiple attributes in a group decision making problem. Chen [31] determined suitable suppliers in the supply chain with linguistic values to assess the ratings and weights of factors according to the best relative closeness coefficient from two directions; this is then used to rank all suppliers.

In summary, researchers have attempted to create a single fuzzy assessment method or integrated MCDM method. However, the usage of the green supply chain criterion was explored less often, and specific industry research on the green supply chain was very limited. It is significant to fuse the traditional investment decision factors and sustainable development factors to realize the sustainable development and extension of the ship supply chain. It is necessary to integrate the influence factors of green ship investment decision making under the background of the green supply chain, strengthen the concept of sustainable development, and pay attention to the concept of sustainable management of the ship life cycle and whole industry chain. On the basis of decision makers' environmental sustainable cognition, the index system of ship investment decision is reconstructed. Hence, this paper attempts to fill the gap by taking full advantage of cognitive preferences and reductions of information loss during evaluations. Fusing uncertain linguistic terms with continuous scores and mapping uncertain linguistic terms to a hierarchical cloud can improve the information utilization efficiency. The dual group decision mechanism merges the crisp scoring and the fuzzy linguistic term, considering both the qualitative natural linguistic assessment and quantitative scoring evaluation. A two-way evaluation mechanism ensures the high performance and makes full use of the hierarchy of cognitive information in selecting among the alternatives. 
This paper is organized as follows. In the next section, a criteria system is constructed. Section 3 focuses on the proposed dual group decision fusion mechanism; the corresponding theory is shown step by step beforehand. Then, a dry bulk carrier is selected for investment based on a performance analysis. In the final section, an example is tested and discussed, while classic and current group methods are employed as comparison methods and discussed.

\section{Criteria System Construction}

Cognition is not only formed in the brain, but also emerges from interaction with the environment. The computation of cognitive information comprises the identification of factor information and the decision environment. The influence factors for the selection of dry cargo ships for investment under a green supply chain have been found using literature references, reports, and public data from the ship industry. According to Sarkis (2003) [32], the green supply chain framework is based on basic environmental awareness. Ship investment selection involves green supply chain management, green cooperation and collaboration, consumer management, and green supply chain management $[33,34]$. Meanwhile, Yang [35] explored the relationship between green performance and green practices in shipping. Then, Rostamzadeh et al. [6] pointed out that green practice consists of ecology design, reverse logistics, and internal environment management. Under the environment of the green supply chain, the decision making of dry bulk carrier investment is based on the external environmental cognition. Therefore, it is necessary to identify not only green technology and the green purchase of enterprises themselves, but also the environmentally-friendly practices, green policy norms, and sustainable development performance brought about by the interaction between enterprises and the external environment on cooperation and coordination ability. The decision making indicators of dry bulk shipping investment would focus on the technology and purchasing ability, such as green material procurement, environmental cooperation, and green market competition. The green purchasing aims to make sure that the purchased items or raw material have desirable environmental attributes such as reusability, product recovery, green packaging, etc. Green competition refers to the long-term dominant position of competitiveness based on the vision of sustainable development, comprising the technology and ecological design superiority, utilization improvement, and green market environment advantage.

The coordinance factors between shipping enterprises and environment include green practice, environmental development policy, environmental performance, and cooperation within green supply chain partners. The green cooperation and collaboration is collaboration that is driven by green and environmentally-friendly development, including coordination with suppliers and customers, information sharing with green partners, and also the inventive mechanism of supply chain cooperation. Green practice requires more coordination with immediate customers and end-consumers, along with greater interaction with suppliers when designing and developing new products. It comprises a series of inter-organizational activities arising from different options for improving environmental management, including product recovery processing capacity, the reverse logistics, environmentally-friendly transportation, etc. Green policy uses environmental standardization to act as an important role in supporting the implementation of relevant policies and systems, which leads us to think about how to implement environmental management system standards to assist the green supply chain management practices. Green performance is related to cost consumption, investment recovery, and pollution treatment of environment sustainability metrics. The details are found in Table 1. 
Table 1. Decision index for investment selection.

\begin{tabular}{|c|c|c|c|}
\hline Influence Factor & Code & Indicators & Literature \\
\hline \multirow{8}{*}{$\begin{array}{l}\text { Green } \\
\text { practice }\end{array}$} & u1 & Senior managers promise & \multirow{8}{*}{$\begin{array}{l}\text { Kehbila [36], Chan [37] } \\
\text { Victor [38] } \\
\text { Zsidisin et al. [39], } \\
\text { Rostamzadeh et al. [6] } \\
\text { Sarkis [32], Berling et al. [40] } \\
\text { Shang et al. [41] } \\
\text { Li [42] } \\
\text { Zhu et al. [43] }\end{array}$} \\
\hline & u2 & Environmentally-friendly transportation & \\
\hline & & & \\
\hline & u3 & Reverse logistics & \\
\hline & $\mathrm{u} 4$ & Resource and environment protection agent & \\
\hline & u5 & Green stock & \\
\hline & u6 & Product recovery processing capacity & \\
\hline & u7 & Green education and training & \\
\hline \multirow{4}{*}{$\begin{array}{l}\text { Green } \\
\text { policy }\end{array}$} & $\mathrm{u} 8$ & Environmental certification, ISO 14000 certification & Lai et al. [44] \\
\hline & u9 & Company policies and procedures & Lai et al. [44] \\
\hline & u10 & Ship design and compliance & Keane et al. [45] \\
\hline & u11 & Shipping documentation & Tseng [46] \\
\hline \multirow{3}{*}{$\begin{array}{l}\text { Green } \\
\text { purchasing }\end{array}$} & u12 & Green raw materials and equipment & Zsidisin et al. [39] \\
\hline & u13 & Green packaging & Rao et al. [47] \\
\hline & u14 & Green recovery & Khan et al. [48] \\
\hline \multirow{4}{*}{$\begin{array}{l}\text { Green } \\
\text { performance }\end{array}$} & u15 & \multirow{4}{*}{$\begin{array}{l}\text { Environmental performance and } \\
\text { economic performance } \\
\text { Ecological design practice and investment recovery } \\
\text { Pollution treatment cost and environmental } \\
\text { performance evaluation } \\
\text { Cost of consumption }\end{array}$} & Zhu et al. [33], Rao [47] \\
\hline & u16 & & Zhu et al. $[34,43]$ \\
\hline & u17 & & Yeh [49] \\
\hline & u18 & & Tsai et al. [50] \\
\hline \multirow{7}{*}{$\begin{array}{l}\text { Green } \\
\text { competition }\end{array}$} & u19 & Environmentally-friendly technology and materials & \multirow{7}{*}{$\begin{array}{l}\text { Awasthi et al. [51] } \\
\text { Singh et al. [52] } \\
\text { Chan et al. [53] } \\
\text { Rao et al. [47], } \\
\text { Papapostolou et al. [54] } \\
\text { Srivastava [55] } \\
\text { Zhang et al. [56] }\end{array}$} \\
\hline & u20 & Level of information technology & \\
\hline & u21 & Green advertising and green market & \\
\hline & $u 22$ & Quality and productivity capacity & \\
\hline & $\mathrm{u} 22$ & utilization improvement & \\
\hline & u23 & Green production/ecological design & \\
\hline & u24 & Green public praise & \\
\hline \multirow{6}{*}{$\begin{array}{l}\text { Green } \\
\text { cooperation } \\
\text { and } \\
\text { collaboration }\end{array}$} & $\mathrm{u} 25$ & Coordination with suppliers and customers & Vachon et al. $[57,58]$ \\
\hline & 126 & Market and information sharing & Awasthi et al. [51], \\
\hline & $\mathrm{u} \angle 0$ & with green partners & Zaheer et al. [59] \\
\hline & u27 & Green customer & Laari et al. [60] \\
\hline & u28 & Greening supplier & Awasthi et al. [51], Hsu et al. [61] \\
\hline & u29 & Incentive mechanism of supply chain & Fritsch et al. [62] \\
\hline
\end{tabular}

\section{Methodology}

When representing group decision making based on cognitive information, it is most natural to utilize a natural linguistic term combined with precise values to select the best ship investment alternative. We propose a dual group decision fusion mechanism consisting of a cloud model, prospect theory, consensus of alternatives, and performance of alternatives. A cloud model reflects uncertain phenomena in the natural sciences. In this case, a cloud model combined with prospect theory is employed to represent the bounded rationality of DMs, which is fully integrated with the uncertainty of the decision attributes. A model for the degree of consensus ensures the effectiveness of decision making and reduces the inconsistency and bias of DMs. Finally, TOPSIS theory is utilized to illustrate the performance of the decision method and determine a ranking of alternatives.

\subsection{Problem Description}

There are significant differences in knowledge and experience among DMs. In addition, the individual preferences and risk attitudes of decision makers will also result in biases. Therefore, a group decision mechanism for the selection of dry bulk carriers for investment under the green supply chain is constructed. The set of alternatives is $A=\left\{a_{1}, a_{2}, \cdots, a_{m}\right\}(m \geq 2)$, and the associated criteria set is $U=\left\{u_{1}, u_{2}, \cdots, u_{n}\right\}(n>2)$, where the criteria are mutually independent. The continuous scoring evaluation set is $X=\left\{x_{1}, x_{2}, \cdots, x_{n}\right\}(n>2)$. The weight vector of the criteria layer is $\omega=\left\{\omega_{1}, \omega_{2}, \cdots, \omega_{n}\right\}$, which satisfies the constraint condition $\sum_{i=1}^{n} \omega_{i}=1, \omega_{i} \geq 0, i=1,2, \cdots, n$ along with some other constraints. The possible natural state $f^{j}=\left\{f_{1}^{j}, f_{2}^{j}, \cdots, f_{s}^{j}\right\}$ of criterion $u_{j}$ 
has probability $p_{l}^{j}$ under state $f_{l}^{j}(1 \leq l \leq s)$. For the set of DMs $E=\left\{e_{1}, e_{2}, \cdots, e_{t}\right\}(t \geq 2), x_{i j l}^{k}$ represents the linguistic variable evaluation of alternative $a_{i}$ under the criterion $u_{j}$ in the state $f_{l}^{j}$. Then, the optimal scheme ranking is a prospect value decision framework with higher levels of satisfaction and performance.

\subsection{Cloud Model}

The cloud model performs the quantitative transformation of scores, which is the key to a unified evaluation based on the scores and linguistic terms. A cloud is composed of cloud droplets. One cloud droplet cannot reflect the characteristics of a qualitative concept, but a cloud consisting of many cloud droplets can represent the ambiguity of the scheme. Usually, the cloud model is denoted by cloud droplets of the form $C(E x, E n, H e)$. Here, $E x$ is the expected value, which reflects the mathematical expectation of the qualitative concept, and $E n$ is the entropy of the fuzzy qualitative concept. He is the hyper entropy, which reflects the randomness of dispersion and the degree of certainty. The overall distribution of an exact number of cloud droplets reflects the ambiguity and randomness of the cloud transformation. The cloud transformation can be performed in two main ways: one is through direct generation, such as with the golden section, and the other is through indirect generation, such as with inverse cloud generation. The cloud model deals with uncertain transformations of qualitative concepts and quantitative descriptions based on the cloud operation.

Suppose that DMs give the linguistic term a grade of $n=5$ and make an effective domain $U=[-10,10]$. The golden section method of cloud transformation generates $n$ clouds corresponding to the linguistic term set. The intermediate complete cloud is $C_{0}\left(E x_{0}, E n_{0}, H e_{0}\right)$. The left and right adjacent clouds are $C_{-2}\left(E x_{-2}, E n_{-2}, H e_{-2}\right), C_{-1}\left(E x_{-1}, E n_{-1}, H e_{-1}\right), C_{1}\left(E x_{1}, E n_{1}, H e_{1}\right)$, and $C_{2}\left(E x_{2}, E n_{2}, H e_{2}\right)$. The left-side clouds are semi-descending clouds, indicating some poor qualitative concepts, and the right-side clouds indicate some good qualitative concepts. Therefore, according to the domain, the expected values for the five clouds are $X_{\min }, E x_{0}+0.382 \times\left(X_{\min }+X_{\max }\right) / 2,\left(X_{\min }+\right.$ $\left.X_{\max }\right) / 2, E x_{0}-0.382 \times\left(X_{\min }+X_{\max }\right) / 2$, and $X_{\max }$. The golden section for generating a cloud on five linguistic grades is shown in Table 2.

Table 2. Numerical characteristics of a cloud model.

\begin{tabular}{cccc}
\hline Cloud Model & $\boldsymbol{E x}$ & $\boldsymbol{E n}$ & $\boldsymbol{H e}$ \\
\hline$C_{2}\left(E x_{2}, E n_{2}, H e_{2}\right)$ & 10 & 2.0604 & 0.1309 \\
$C_{1}\left(E x_{1}, E n_{1}, H e_{1}\right)$ & 3.82 & 1.2733 & 0.0809 \\
$C_{0}\left(E x_{0}, E n_{0}, H e_{0}\right)$ & 0 & 0.7869 & 0.05 \\
$C_{-1}\left(E x_{-1}, E n_{-1}, H e_{-1}\right)$ & -3.82 & 1.2733 & 0.0809 \\
$C_{-2}\left(E x_{-2}, E n_{-2}, H e_{-2}\right)$ & -10 & 2.0604 & 0.1309 \\
\hline
\end{tabular}

To make up for the numerical characteristics of the cloud model given directly, e.g., through the golden section, a reverse cloud generator is provided, and numerical characteristics of the cloud model are computed based on cloud droplets. The first order central moments and variance are calculated based on the cloud droplets as follows:

- The first order central moment of the input data $B=\frac{1}{m} \sum_{i=1}^{m}\left|x_{i}-\bar{x}\right|$

- $\quad$ The variance $S^{2}=\frac{1}{m-1} \sum_{i=1}^{m}\left(x_{i}-\bar{x}\right)^{2}$

- $\quad$ The expected value $E \hat{x}=\bar{x}=\frac{1}{m} \sum_{i=1}^{m} x_{i}$

- The entropy of the cloud $E \hat{n}=\sqrt{\pi / 2} \times B$

- The hyper entropy of the cloud $H \hat{e}=\sqrt{\left(S^{2}-E \hat{n}\right)}$

The cloud is depicted by three numbers; therefore, the comparison of clouds needs a special definition. 
Definition 1. (Cloud comparison) Suppose $C_{1}\left(E x_{1}, E n_{1}, H e_{1}\right)$ and $C_{2}\left(E x_{2}, E n_{2}, H e_{2}\right)$ are two one-dimensional normal clouds in the domain. The positive ideal cloud $C^{*}\left(\max _{i} E x_{i}, \max _{i} E n_{i}, \max _{i} H e_{i}\right), i=$ 1,2. $P\left(C_{1} \geq C_{2}\right)$ is the probability, which can be expressed as:

$$
P\left(C_{1} \geq C_{2}\right)=1-\frac{\left.D\left(C^{*}, C_{1}\right)\right)}{D\left(C^{*}, C_{1}\right)+D\left(C^{*}, C_{2}\right)}
$$

where $D\left(C^{*}, C_{1}\right)$ and $D\left(C^{*}, C_{2}\right)$ are the Hamming distances between $C_{1}$ or $C_{2}$, respectively, and $C^{*}$. If $P\left(C_{1} \geq\right.$ $\left.C_{2}\right) \geq 0.5$, then $C_{1} \geq C_{2}$; otherwise, $C_{1}<C_{2}$.

\subsection{Prospect Theory Based on the Cloud Model}

Prospect theory, proposed by Kahneman and Tversky [63], is the most popular form of behavioral decision theory. It can be compared with expected utility theory when solving the uncertainty decision problem. Prospect theory puts forward the concept of a reference point that considers the risk attitudes of decision makers. The core idea of a prospect value consists of a value function and a weight function that reflect the bounded rationality of the DMs in the decision process.

The cloud prospect decision model integrates prospect theory with the cloud model. A cloud comparison of the cloud model is embedded in the value function and weight function from prospect theory. The cloud prospect decision matrix $V^{k}$ for the $k^{\text {th }} \mathrm{DM}$ is composed of a cloud prospect value function $v(C)$ and a cloud prospect weight function $\pi(p)$. The cloud prospect value $V_{i j}^{k}$ for attribute $j$ of alternative $i$ is:

$$
V_{i j}^{k}=\sum_{l=1}^{s} \sum_{z=1, z \neq i}^{m} \pi_{i j l}^{k}\left(p_{l}^{j}\right) v\left(C_{z j l}^{k}\right)
$$

Taking the decision maker's psychology as the starting point, the characteristics of different alternatives are compared. This paper explores the prospect values of different alternatives under various conditions and reflects the decision maker's risk preference and cognition capability through the value function and the weight function. We have:

$$
v\left(C_{z j l}^{k}\right)= \begin{cases}\left(D\left(C_{i j l}^{k}, C_{z j l}^{k}\right)\right)^{\alpha}, & C_{z j l}^{k} \geq C_{i j l}^{k} \\ -\lambda\left(D\left(C_{i j l}^{k}, C_{z j l}^{k}\right)\right)^{\gamma}, & C_{z j l}^{k}<C_{i j l}^{k}\end{cases}
$$

where $v(C)$ is formed by the subjective perception of the DMs and $\lambda$ is the loss aversion coefficient. When $\lambda>1$, the DM is more sensitive to loss. The parameters $0 \leq \alpha, \gamma \leq 1$ reflect the degree of concavity and convexity, respectively, of the regional value function for gains and losses; it is relatively shallow in that region, which means it is a more stable reflection of value.

Cloud prospect theory is more reasonable than expected utility theory because of the introduction of the decision weight function $\pi(p)$ :

$$
\pi_{i j}^{k}\left(p_{l}^{j}\right)= \begin{cases}\left(p_{l}^{j}\right)^{\tau} /\left[\left(p_{l}^{j}\right)^{\tau}+\left(1-p_{l}^{j}\right)^{\tau}\right]^{1 / \tau}, & C_{i j l}^{k} \geq C_{z j l}^{k} \\ \left(p_{l}^{j}\right)^{\delta} /\left[\left(p_{l}^{j}\right)^{\delta}+\left(1-p_{l}^{j}\right)^{\delta}\right]^{1 / \delta}, & C_{i j l}^{k}<C_{z j l}^{k}\end{cases}
$$

where $\tau$ is a risk revenue attribute coefficient and $\delta$ is a risk loss attribute coefficient. As a nonlinear treatment of probabilities in rank-dependent models that incorporate the relative positions of outcomes for different behaviors, as in expected utility theory, prospect theory involves a weight function [64] $\pi_{i j}^{k}$ that uniquely determines the probabilities. The weight function $\pi(p)$ reflects the probability weight function considering the risk attitudes of the DMs. When the reference point is set up, it assumes a particular outcome, since DMs prefer and disprefer gains and losses, respectively. A positive utility corresponds to a gain; otherwise, the outcome strictly dispreferred in comparison to the reference point is the losses with negative utility values. 


\subsection{Group Decision Consensus Degree}

As the DMs differ in their preferences and cognitive abilities, a consensus measurement is introduced to measure the cloud prospect consistency (CPC) between DMs for each alternative. The consensus measurement operates at the DM level and aggregates the DMs for each alternative. According to the consistency threshold, a correction scheme can then be selected. The CPC operates at the decision maker level using a specified consistency threshold to provide a preliminary correction scheme. The calculation of the CPC is mainly divided into two steps.

1. Aggregation: Calculate the cloud prospect decision matrix of each DM. The group cloud prospect decision matrix $V^{c}$ is computed by:

$$
V_{i j}^{c}=\sum_{k=1}^{t} V_{i j}^{k} / t
$$

where $i$ denotes an alternative and $j$ denotes an attribute.

2. Cloud prospect consensus degree: Classically, consensus is defined as the full and unanimous agreement of all decision makers regarding all possible alternatives. The CPC used in this paper is based on the cloud model and prospect theory, as shown in Equation (7). First, the consensus of alternative $i$ for DM $e_{k}$ with group decision matrix $V^{c}$ is:

$$
\operatorname{CON}\left(V_{i}^{k}\right)=\sqrt{\frac{1}{n} \sum_{j=1}^{n}\left(\frac{V_{i j}^{k}-V_{i j}^{c}}{\left(\max _{g}\left\{V_{i g}^{k}-V_{i g}^{k}\right\}-\min _{g}\left\{V_{i g}^{k}-V_{i g}^{c}\right\}+\varepsilon\right) * n}\right)^{2}}, g=1,2, \ldots, n
$$

where $\varepsilon$ is a correction coefficient, usually assigned a value of 1 . The CPC of alternative $i$ for all DMs and the CPC of all DMs are computed as:

$$
\operatorname{CPC}\left(a_{i}\right)=1-\frac{1}{t} \sum_{k=1}^{t} \operatorname{CON}\left(V_{i}^{k}\right)
$$

Let the consensus degree threshold of the CPC for group decisions be $\beta$. If $C P C\left(a_{i}\right)<\beta$, then adjust $a_{i}$ according to the minimum CPC to adjust the alternative.

\subsection{Dual Group Decision Fusion Mechanism}

It is difficult, but necessary, to achieve consensus among all DMs in group decision making. Usually, feedback regulation is introduced to allow the DMs to revise their evaluations. In some cases, it may be repeated many times to get a consensus of all DMs. This reduces the general applicability of the group decision making method. To improve the efficiency of investment selection, we instead make a reasonable linguistic variable evaluation. As a reasonable supplement, we use a continuous scoring evaluation based on cognitive capacity under the uncertain environment. Therefore, the linguistic variable evaluation and accurate scoring evaluation are integrated into a unified evaluation term; based on this, the cloud prospect values of alternatives with various criteria are determined. The best investment alternative among the dry bulk carriers is determined through the relative proximity to the ideal solution based on the cloud prospect value function. The linguistic assessment, cloud model transformation and prospect value constitute the main components of the dual group decision fusion mechanism model. The dual group decision fusion mechanism starts with both linguistic variable evaluation and continuous scoring evaluation and aims to improve decision efficiency and accuracy. It involves the following main steps.

First, set up the linguistic terms set and carry out the linguistic evaluation.

Second, set up an interval score in $[0,100]$ and carry out the continuous scoring evaluation.

Third, build a hierarchical cloud. Compute the scoring value corresponding to each linguistic term, and use the reverse cloud generator to generate the expected value, entropy, and 
hyperentropy of the cloud. All generated clouds constitute hierarchical clouds of the cloud prospect group decision model.

Fourth, build a unified frame for the linguistic terms, integrating the transformed hierarchical and linguistic variables into a unified evaluation term.

Fifth, compute the prospect value of each alternative. Use Equations (1)-(4) to calculate the cloud prospect values with the generated hierarchical clouds under the unified evaluation term.

Sixth, calculate the consensus degree based on the CPC. Use Equation (5) to aggregate the decision matrices $V_{i j}^{k}$ of all the DMs, and then, calculate the CPC for each alternative through Equations (6) and (7).

Seventh, according to the consensus degree threshold, adjust the difference or disagreement attribute to satisfy the accepted threshold.

\section{Performance Analysis}

As a newly-proposed method, the dual group decision fusion method requires a reasonable standard to evaluate its performance. The ranking results for investment projects and the corresponding consensuses can only provide a partial evaluation of the advantages and disadvantages of the proposed method. Some quantitative indicators are used to evaluate the method more comprehensively. TOPSIS (technique for order performance by similarity to the ideal solution) is known for solving MCDM problems and has been widely accepted for investment selection due to its simplicity and applicability, as well as its higher sensitivity in issues involving various criteria $[1,65]$. Therefore, the positive ideal and negative ideal solutions (PIS and NIS) from the technique for order performance by similarity to ideal solution are used to evaluate the method based on prospect value. The relative closeness to the PIS depends on the final sorting of all the alternatives.

Step 1: construct the normalized decision matrix of the prospect value on each attribute for each DM. The normalization for the benefit criteria will be represented as:

$$
z_{i j}^{k}=V_{i j}^{k} / V_{j}^{k^{*}}, V_{j}^{k^{*}}=\max _{i}\left\{V_{i j}^{k}\right\}
$$

For cost criteria, the normalization will be

$$
z_{i j}^{k}=\frac{\min _{i}\left\{V_{i j}^{k}\right\}}{V_{i j}^{k}}
$$

Step 2: determine the ideal and negative ideal solution $Z^{k+}$ (PIS) and $Z^{k-}$ (NIS), respectively. There is a PIS and NIS for each DM on two kinds of decision attributes. We have:

$$
\begin{aligned}
& Z^{k+}=\left\{z_{1}^{k+}, \cdots, z_{n}^{k+}\right\}=\left\{\max _{i} z_{i j}^{k}\left|j \in J, \min _{i} z_{i j}^{k}\right| j \in J^{\prime}\right\} \\
& Z^{k-}=\left\{z_{1}^{k-}, \cdots, z_{n}^{k-}\right\}=\left\{\min _{i} z_{i j}^{k}\left|j \in J, \max _{i} z_{i j}^{k}\right| j \in J^{\prime}\right\}
\end{aligned}
$$

where $J$ is associated with the benefit criteria and $J^{\prime}$ is associated with the cost criteria.

Step 3: the separation measurement from the ideal and negative ideal solutions $\bar{S}_{i}^{+}$and $\bar{S}_{i}^{-}$, respectively. For a given weight assignment coefficient $\omega_{i}$ of the criteria, the weighted similarity of the prospect value comes from Equations (12) and (13). Construct a similarity (distance) measurement for the DMs between individuals and groups. Here, the individual similarity is for an individual DM of alternative $i$. 


$$
\begin{aligned}
& \bar{S}_{i}^{k+}=\left(\sum_{j=1}^{n} \omega_{j}\left(z_{i j}^{k}-z_{n}^{k+}\right)^{p}\right)^{1 / p} \\
& \bar{S}_{i}^{k-}=\left(\sum_{j=1}^{n} \omega_{j}\left(z_{i j}^{k}-z_{n}^{k-}\right)^{p}\right)^{1 / p}
\end{aligned}
$$

When $p=2$, the similarity metric is the Euclidean distance. In addition, the group similarity is the aggregation of the individual DMs. The group similarity measure for each alternative will be computed through an operation $\otimes$ on all the DMs. The operation $\otimes$ is the geometric mean; the group metric will be:

$$
\begin{aligned}
& \bar{S}_{i}^{+}=\left(\Pi_{k=1}^{t} S_{i}^{k+}\right)^{1 / t} \\
& \bar{S}_{i}^{-}=\left(\Pi_{k=1}^{t} S_{i}^{k-}\right)^{1 / t}
\end{aligned}
$$

Step 4: calculate the relative closeness to determine the ideal solution for the group. The relative closeness is computed to PIS for alternative $i$ :

$$
\bar{C}_{i}^{*}=\frac{\bar{S}_{i}^{-}}{\bar{S}_{i}^{+}+\bar{S}_{i}^{-}}
$$

where $0 \leq \bar{C}_{i}^{*} \leq 1$. The larger the index, the better the performance of the alternative.

The distinction of the metrics also marks the performance of the decision making in the selection of dry bulk carriers for investment.

\section{Numerical Analysis and Discussion}

\subsection{Case Description}

Dry bulk carrier investment is one of the most important commercial activities of the international shipping industry. Compared to other activities, it requires larger capital investments, longer investment recovery periods, and a higher degree of risk tolerance. When considering a shipowner who would like to invest in one of three dry cargo carriers, $a_{1}$ represents the bulk carrier, $a_{2}$ represents the general cargo carrier, and $a_{3}$ represents the multipurpose vessel. DMs make linguistic evaluations and scoring assessments under three states $f=$ \{poor,fair,good\}, where, for example, the poor state denotes high energy consumption and deficient environmental technology and the good state denotes a high level of green technology. DMs evaluate the decision attribute $u$ under status $f$ with occurrence probability $p$ on the discrete linguistic term set $S=\{1,2,3,4,5\}$, which represents \{quite poor, poor, fair, good, very good . For example, poor implies that the current ship investment is not the best match in terms of the attribute. In Appendix A in the Supplementary Materials, uncertain linguistic evaluations and scoring assessments from 0-100 for dry cargo ships are provided from three experts from the shipbuilding industry and the financial industry.

\subsection{Comparison Method}

To illustrate the effectiveness and significance of the dual group decision fusion mechanism, two representative methods are used as comparison methods to confirm the effectiveness and performance of the mechanism.

\subsubsection{Group Decisions with the Trapezoidal Fuzzy Operation}

One widely-used method of group decision making is the trapezoidal fuzzy method [66-68], and it is the first comparison we use. A fuzzy set, characterized by a fuzzy membership function, 
can provide us with a measurement of the uncertainty and ambiguity in the real world. One of the most popular implementations of fuzzy sets is through triangular or trapezoidal fuzzy numbers with simple calculations. According to the proposed framework of cloud and prospect theory, different attributes with various states are constructed with corresponding probabilities. The same uncertain linguistic term set $S$ is set up. Each linguistic term $S_{i}$ can be expressed as triangular fuzzy number $X_{i}=\left[x_{i}^{L}, x_{i},{ }^{M}, x_{i}^{U}\right]$, where $x_{i}^{L}<x_{i}^{M}<x_{i}^{U}$. The membership function is defined as follows:

$$
\mu_{X_{i}}= \begin{cases}\left(x-x_{i}^{L}\right) /\left(x_{i}^{M}-x_{i}^{L}\right) & x_{i}^{L} \leq x \leq x_{i}^{M} \\ \left(x_{i}^{U}-x\right) /\left(x_{i}^{U}-x_{i}^{M}\right) & x_{i}^{M} \leq x \leq x_{i}^{U} \\ 0 & x \in\left(-\infty, x_{i}^{L}\right) \cup\left(x_{i}^{U},+\infty\right)\end{cases}
$$

Let $\tilde{x}=\left[x_{a}, x_{b}\right]$ be the uncertain linguistic term, where $x_{a}$ and $x_{b}$ are the lower and upper limits, respectively. They can also be expressed as the triangular fuzzy numbers $\left[x_{a}^{L}, x_{a}^{M}, x_{a}^{U}\right]$ and $\left[x_{b}^{L}, x_{b}^{M}, x_{b}^{U}\right]$. Then, the linguistic variable $\tilde{x}=\left[x_{a}, x_{b}\right]$ can be transformed into trapezoidal fuzzy numbers:

$$
\mu(x)= \begin{cases}\left(x-x_{a}^{L}\right) /\left(x_{a}^{M}-x_{a}^{L}\right) & x_{a}^{L} \leq x \leq x_{a}^{M} \\ 1 & x_{a}^{M} \leq x \leq x_{b}^{M} \\ \left(x-x_{b}^{U}\right) /\left(x_{b}^{M}-x_{b}^{U}\right) & x_{b}^{M} \leq x \leq x_{b}^{U} \\ 0 & x \in\left(-\infty, x_{a}^{L}\right) \cup\left(x_{a}^{U},+\infty\right)\end{cases}
$$

Therefore, every interval of linguistic terms can be transformed into a trapezoidal fuzzy linguistic term $\left[x_{a}^{L}, x_{a}^{M}, x_{b}^{M}, x_{b}^{U}\right]$. Meanwhile, the state probability is the interval probability of $(0,1)$. In addition, the interval probability is the given probability plus or minus 0.1 ; for example, if the given probability is 0.2 , then the transformation probability interval is $(0.1,0.3)$. Then, decision making is conducted through the following process:

(1) The interval probability is transformed into the interval probability weight. The interval probability weights $\left(\omega_{1}^{j}, \omega_{2}^{j}, \cdots, \omega_{l}^{j}\right)$ for the $j$ th attribute under the $l$ th status are $\left[\omega\left(\bar{p}_{L_{1}}^{j}, \bar{p}_{U_{1}}^{j}\right)\right],\left[\omega\left(\bar{p}_{L_{2}}^{j}, \bar{p}_{U_{2}}^{j}\right)\right], \cdots,\left[\omega\left(\bar{p}_{L_{l}}^{j}, \bar{p}_{U_{l}}^{j}\right)\right], j=1,2, \cdots, n$. The weight function selection depends on the properties of the attribute. For comparison, the probability intervals are the extension of the definite probabilities, and the trapezoidal fuzzy numbers are the extensions of the uncertain linguistic terms.

(2) Each triangular fuzzy term is transformed into a trapezoidal fuzzy expression. Each attribute is expressed as the uncertain linguistic $\left[x_{a}, x_{b}\right]$ variable and can be transformed into the trapezoidal fuzzy number $\left[x_{a}^{L}, x_{a}^{M}, x_{b}^{M}, x_{b}^{U}\right]$.

(3) The prospect value is computed for the trapezoidal fuzzy assessment of the $j$ th attribute with the $l$ th status under the $i$ th alternative. According to prospect decision theory, the prospect value of an alternative under various criteria depends on the reference point. According to [66-68], a medium point in the linguistic term set should serve as the reference point.

(4) The prospect decision value is obtained by integrating the statuses of the attributes with the alternative. First, the interval probability weight is extended to the trapezoidal fuzzy number. Then, the prospect value is found by integrating the interval probability weight with the prospect value function. This gives us a comprehensive prospect value for the $i$ th alternative under the $j$ th attribute.

\subsubsection{Group Decisions with Fuzzy TOPSIS}

Classic fuzzy TOPSIS is used as the second comparison method. According to [66-68], all ratings and weights are defined by linguistic variables. The main decision process involves the following steps: 
Step 1: Constructing criteria weights. The DMs provide importance weights for each of the factors. The importance levels are then converted into trapezoidal fuzzy numbers based on five levels of importance given in [69]:

$$
\omega=\left(\tilde{\omega}_{j}\right)_{1 \times n}=x_{1} x_{2} \cdots x_{n} /\left[\tilde{\omega}_{1}^{k}, \tilde{\omega}_{2}^{k}, \cdots, \tilde{\omega}_{n}^{k}\right]
$$

where $\tilde{\omega}_{j}^{k}=\left(\frac{\tilde{\omega}_{1}^{1}+\tilde{\omega}_{2}^{2}+\cdots+\tilde{\omega}_{j}^{t}}{t}\right), j=1,2, \ldots, n$.

Step 2: Aggregation of the rating matrix. Each DM evaluates each alternative with respect to each of the criteria using the five scales given in the form of trapezoidal fuzzy numbers:

$$
X=\left(\tilde{f}_{i j}^{k}\right)_{m \times n}=\underset{f_{1}}{f_{m}}\left[\begin{array}{ccc}
\tilde{f}_{11}^{k} & \cdots & \tilde{f}_{1 n}^{k} \\
\vdots & \ddots & \vdots \\
\tilde{f}_{m 1}^{k} & \cdots & \tilde{f}_{m n}^{k}
\end{array}\right]
$$

Then, the aggregate rating of each alternative can be calculated as $\tilde{f}_{i j}=\left(\frac{\tilde{f}_{i j}^{1}+\tilde{f}_{i j}^{2}+\cdots+\tilde{f}_{i j}^{t}}{t}\right)$.

Step 3: Normalizing the decision matrix $\tilde{R}=\left[\tilde{r}_{i j}\right]_{m \times n}$. Paying attention to the different characteristics of each attribute, the normalization of the benefits and costs refers to [69].

Step 4: Weighting the normalized decision matrix $\tilde{v}, \tilde{v}_{i j}=\tilde{r}_{i j} \times \tilde{\omega}_{j}$.

Step 5: Calculating FPISand FNIS.

$$
d_{i}^{*}=\sqrt{\frac{1}{4} \sum_{j=1}^{n}\left(\tilde{v}_{i j}-\tilde{v}_{j}^{*}\right)^{2}}, d_{i}^{-}=\sqrt{\frac{1}{4} \sum_{j=1}^{n}\left(\tilde{v}_{i j}-\tilde{v}_{j}^{-}\right)^{2}}
$$

where $\tilde{v}_{j}^{*}=(1,1,1,1)$ and $\tilde{v}_{j}^{-}=(0,0,0,0)$.

Step 6: Computing relative closeness. The equation is the same as Equation (16).

\subsection{Results and Analysis}

The optimal dry cargo carrier investment decision was made following the golden section of the cloud transformation and numerical characteristics as in Table 3, that is the five discrete linguistic term sets $S=\left\{C_{+2}, C_{+1}, C_{0}, C_{-1}, C_{-2}\right\}$. When referring to the other attributes, DMs make a comparison with other attributes and other states.

According to the dual group decision fusion mechanism, the five reverse clouds and corresponding linguistic terms are generated by a reverse cloud generator based on the linguistic term evaluation and scoring assessment. The expected value is positive and increases along with the discrete linguistic variables.

Table 3. Reverse cloud generator.

\begin{tabular}{ccccc}
\hline Order & Linguistic Term & Expected Value & Entropy & Hyperentropy \\
\hline 1 & $C_{-2}$ & 19.6984 & 3.0176 & 5.0228 \\
2 & $C_{-1}$ & 36.8468 & 3.0852 & 3.1052 \\
3 & $C_{0}$ & 56.9922 & 3.2751 & 3.6096 \\
4 & $C_{+1}$ & 76.5396 & 3.6019 & 4.9476 \\
5 & $C_{+2}$ & 93.0769 & 3.5053 & 2.5213 \\
\hline
\end{tabular}

According to the prospect decision matrix, Equations (4)-(6), and Equations (8) and (9), and considering the loss aversion psychology and risk attitude of each expert, the normalized individual prospect value matrix of alternative $i$ for three decision makers are as follows (Tables 4-6). 
Table 4. Normalized prospect value matrix of the alternatives for DM1.

\begin{tabular}{ccccccccccc}
\hline & $\mathbf{u} 1$ & $\mathbf{u} 2$ & $\mathbf{u} 3$ & $\mathbf{u 4}$ & $\mathbf{u} 5$ & $\mathbf{u 6}$ & $\mathbf{u} 7$ & $\mathbf{u} 8$ & $\mathbf{u} 9$ & $\mathbf{u 1 0}$ \\
\hline$V_{1}$ & 0.4746 & 0.8087 & 0.9610 & 1.0000 & 0.6678 & 0.3127 & 1.0000 & 0.5344 & 0.9284 & 0.8139 \\
$V_{2}$ & 0.6197 & 1.0000 & 0.3545 & 0.5418 & 0.5065 & 0.4652 & 0.8974 & 0.5190 & 0.9274 & 1.0000 \\
$V_{3}$ & 1.0000 & 0.7331 & 1.0000 & 0.8413 & 1.0000 & 1.0000 & 0.7188 & 1.0000 & 1.0000 & 0.7436 \\
\hline & $\mathbf{u 1 1}$ & $\mathbf{u 1 2}$ & $\mathbf{u 1 3}$ & $\mathbf{u 1 4}$ & $\mathbf{u 1 5}$ & $\mathbf{u 1 6}$ & $\mathbf{u 1 7}$ & $\mathbf{u 1 8}$ & $\mathbf{u 1 9}$ & $\mathbf{u 2 0}$ \\
\hline$V_{1}$ & 0.6558 & 0.3466 & 1.0000 & 0.5997 & 1.0000 & 0.5237 & 0.3974 & 0.9225 & 0.7789 & 1.0000 \\
$V_{2}$ & 0.9232 & 1.0000 & 0.3665 & 1.0000 & 0.6256 & 0.4523 & 0.3523 & 0.5345 & 1.0000 & 0.8017 \\
$V_{3}$ & 1.0000 & 0.9795 & 0.8033 & 0.8980 & 0.5634 & 1.0000 & 1.0000 & 1.0000 & 0.8184 & 0.0000 \\
\hline & $\mathbf{u 2 1}$ & $\mathbf{u 2 2}$ & $\mathbf{u 2 3}$ & $\mathbf{u 2 4}$ & $\mathbf{u 2 5}$ & $\mathbf{u 2 6}$ & $\mathbf{u 2 7}$ & $\mathbf{u 2 8}$ & $\mathbf{u 2 9}$ & \\
\hline$V_{1}$ & 1.0000 & 0.4213 & 1.0000 & 1.0000 & 0.6881 & 0.9910 & 0.6687 & 0.6442 & 0.8577 & \\
$V_{2}$ & 0.4688 & 1.0000 & 0.2388 & 0.4257 & 1.0000 & 0.1493 & 0.9041 & 1.0000 & 0.2717 & \\
$V_{3}$ & 1.0000 & 0.6916 & 0.9907 & 0.5361 & 0.8072 & 1.0000 & 1.0000 & 0.7501 & 1.0000 & \\
\hline
\end{tabular}

Table 5. Normalized prospect value matrix of the alternatives for DM2.

\begin{tabular}{ccccccccccc}
\hline & $\mathbf{u 1}$ & $\mathbf{u} 2$ & $\mathbf{u} 3$ & $\mathbf{u 4}$ & $\mathbf{u} 5$ & $\mathbf{u 6}$ & $\mathbf{u} 7$ & $\mathbf{u} 8$ & $\mathbf{u 9}$ & $\mathbf{u 1 0}$ \\
\hline$V_{1}$ & 1.0000 & 0.0000 & 0.6893 & 0.9260 & 0.5048 & 1.0000 & 0.3701 & 0.6059 & 0.6744 & 0.7894 \\
$V_{2}$ & 0.8731 & 1.0000 & 0.5488 & 1.0000 & 0.9434 & 0.6988 & 1.0000 & 1.0000 & 0.7433 & 1.0000 \\
$V_{3}$ & 0.6664 & 0.9079 & 1.0000 & 0.2431 & 1.0000 & 0.9743 & 0.9587 & 0.8134 & 1.0000 & 0.0892 \\
\hline & $\mathbf{u 1 1}$ & $\mathbf{u 1 2}$ & $\mathbf{u 1 3}$ & $\mathbf{u 1 4}$ & $\mathbf{u 1 5}$ & $\mathbf{u 1 6}$ & $\mathbf{u 1 7}$ & $\mathbf{u 1 8}$ & $\mathbf{u 1 9}$ & $\mathbf{u 2 0}$ \\
\hline$V_{1}$ & 1.0000 & 0.7684 & 0.3916 & 0.9609 & 0.9235 & 0.5675 & 1.0000 & 0.4894 & 1.0000 & 0.8461 \\
$V_{2}$ & 0.5547 & 0.6212 & 0.6916 & 0.4674 & 0.5286 & 1.0000 & 0.6041 & 0.4166 & 0.6177 & 1.0000 \\
$V_{3}$ & 0.6837 & 1.0000 & 1.0000 & 1.0000 & 1.0000 & 0.7633 & 0.4949 & 1.0000 & 0.8211 & 1.0000 \\
\hline & $\mathbf{u 2 1}$ & $\mathbf{u 2 2}$ & $\mathbf{u 2 3}$ & $\mathbf{u 2 4}$ & $\mathbf{u 2 5}$ & $\mathbf{u 2 6}$ & $\mathbf{u 2 7}$ & $\mathbf{u 2 8}$ & $\mathbf{u 2 9}$ & \\
\hline$V_{1}$ & 0.0559 & 0.4664 & 1.0000 & 0.6097 & 1.0000 & 0.7670 & 0.6279 & 0.6026 & 1.0000 & \\
$V_{2}$ & 1.0000 & 0.8054 & 0.9285 & 1.0000 & 0.7878 & 1.0000 & 1.0000 & 0.6206 & 0.4809 & \\
$V_{3}$ & 0.7975 & 1.0000 & 0.8190 & 1.0000 & 0.3663 & 0.4722 & 0.2388 & 1.0000 & 0.5882 & \\
\hline
\end{tabular}

Table 6. Normalized prospect value matrix of the alternatives for DM3.

\begin{tabular}{ccccccccccc}
\hline & $\mathbf{u 1}$ & $\mathbf{u 2}$ & $\mathbf{u} \mathbf{3}$ & $\mathbf{u 4}$ & $\mathbf{u} \mathbf{5}$ & $\mathbf{u 6}$ & $\mathbf{u} 7$ & $\mathbf{u} 8$ & $\mathbf{u} 9$ & $\mathbf{u 1 0}$ \\
\hline$V_{1}$ & 0.5329 & 0.6892 & 0.3837 & 1.0000 & 0.9679 & 0.1242 & 0.9909 & 0.5443 & 0.9378 & 0.5504 \\
$V_{2}$ & 1.0000 & 0.6474 & 1.0000 & 0.6678 & 1.0000 & 1.0000 & 1.0000 & 1.0000 & 1.0000 & 1.0000 \\
$V_{3}$ & 0.7452 & 1.0000 & 0.6398 & 0.1229 & 0.8390 & 0.7000 & 0.1212 & 0.6564 & 0.9838 & 0.6957 \\
\hline & $\mathbf{u 1 1}$ & $\mathbf{u 1 2}$ & $\mathbf{u 1 3}$ & $\mathbf{u 1 4}$ & $\mathbf{u 1 5}$ & $\mathbf{u 1 6}$ & $\mathbf{u 1 7}$ & $\mathbf{u 1 8}$ & $\mathbf{u 1 9}$ & $\mathbf{u 2 0}$ \\
\hline$V_{1}$ & 0.5436 & 0.7691 & 0.7262 & 0.6136 & 0.0935 & 1.0000 & 0.4551 & 0.4145 & 0.5766 & 1.0000 \\
$V_{2}$ & 1.0000 & 0.6721 & 0.6527 & 0.8452 & 0.8657 & 1.0000 & 0.7276 & 0.4145 & 1.0000 & 0.4398 \\
$V_{3}$ & 0.1649 & 1.0000 & 1.0000 & 1.0000 & 1.0000 & 0.4501 & 1.0000 & 1.0000 & 0.0000 & 0.4868 \\
\hline & $\mathbf{u 2 1}$ & $\mathbf{u 2 2}$ & $\mathbf{u 2 3}$ & $\mathbf{u 2 4}$ & $\mathbf{u 2 5}$ & $\mathbf{u 2 6}$ & $\mathbf{u 2 7}$ & $\mathbf{u 2 8}$ & $\mathbf{u 2 9}$ & \\
\hline$V_{1}$ & 0.6918 & 0.4850 & 0.5448 & 0.6120 & 1.0000 & 1.0000 & 0.9928 & 0.8591 & 1.0000 & \\
$V_{2}$ & 1.0000 & 1.0000 & 1.0000 & 0.5350 & 0.8697 & 0.2531 & 1.0000 & 0.4790 & 0.5068 & \\
$V_{3}$ & 0.9225 & 0.7416 & 0.5354 & 1.0000 & 0.3388 & 0.4941 & 0.4390 & 1.0000 & 0.2771 & \\
\hline & & & & & & & & & &
\end{tabular}

According to Equations (6) and (7), the consensuses of the three alternatives were 0.9960, 0.9962, and 0.9959, which are all greater than the common thresholds of 0.9 $(\beta=0.9)$ and $0.95(\beta=0.95)$. The higher level of consensus shows the credibility of the decision making process. The set of weights for the given 29 attributes was $\{0.01,0.03,0.01,0.01,0.1,0.01,0.005,0.08,0.1,0.01,0.0058,0.06,0.009,0.01,0.1,0.01,0.0362,0.01,0.05,0.01$, $0.005,0.019,0.0045,0.08,0.007,0.055,0.045,0.025,0.0035\}$

The set of relative closeness values for the three alternatives was $\{0.4643,0.5326,0.5675\}$. Obviously, there are large distinctions among the $C_{i}$ values, which shows a rank of $a_{3}>a_{2}>a_{1}$; namely, the multipurpose vessel was superior to the general cargo carrier, and the general cargo carrier was superior to the bulk carrier. Obviously, the multipurpose vessel had the best investment 
performance, namely it had the best prospect value on dry bulk carrier investment and was closest to the optimal investment scheme. At the same time, the performance measurement could be used to motivate the current program to further improve and optimize, and to motivate enterprise's high-value goal orientation. The investment performance of multi-purpose ships increased by $22.23 \%$ compared with the bulk carrier, and the general cargo carrier increased by $14.71 \%$ compared with the bulk carrier.

\subsection{Method Comparison and Evaluation}

When there are five linguistic term in $S$, the transformation method from the uncertain linguistic variables to triangular fuzzy numbers is as follows, as in [68]:

$$
\begin{cases}x_{0}=0 & \\ x_{i}^{L}=(i-1) / 4 & 1 \leq i \leq 4 \\ x_{i}^{M}=i / 4 & 0 \leq i \leq 4 \\ x_{i}^{U}=(i+1) / 4 & 0 \leq i \leq 3 \\ x_{5}^{U}=1 & \end{cases}
$$

The corresponding relationship between the linguistic variables and the triangular fuzzy numbers was $x_{0}=(0,0,0.25), x_{1}=(0,0.25,0.5), x_{2}=(0.25,0.5,0.75), x_{3}=(0.5,0.75,1), x_{4}=(0.75,1,1)$.

With regard to the performance of the alternative selection, according to Equations (12) and (13), the PIS and NIS for individual DM and the similarity or distance metrics for the individuals and the group are as follows.

$$
\begin{array}{rr}
\text { NIS } & \text { PIS } \\
\bar{S}^{1}=\left[\begin{array}{ll}
0.3983 & 0.2956 \\
0.2652 & 0.4302 \\
0.4209 & 0.2699
\end{array}\right] & \bar{S}^{2}=\left[\begin{array}{ll}
0.2438 & 0.3788 \\
0.3900 & 0.2781 \\
0.3994 & 0.2636
\end{array}\right] \\
\bar{S}^{3}=\left[\begin{array}{ll}
0.3241 & 0.4319 \\
0.4716 & 0.2756 \\
0.3681 & 0.3852
\end{array}\right] & \bar{S}=\left[\begin{array}{ll}
0.3157 & 0.3643 \\
0.3654 & 0.3207 \\
0.3955 & 0.3015
\end{array}\right]
\end{array}
$$

The weighted function value took the form of the trapezoidal fuzzy number, and the alternatives were weighted based on the expected value of the trapezoidal fuzzy numbers. The separation measure from the ideal and negative ideal solutions for the group DMs is as follows:

$$
\bar{S}_{1}=\left[\begin{array}{cl}
\text { NIS } & \text { PIS } \\
0.3984 & 0.3899 \\
0.3737 & 0.3601 \\
0.3901 & 0.3816
\end{array}\right] \quad \bar{S}_{2}=\left[\begin{array}{rl}
17.0052 & 13.7102 \\
16.5062 & 14.2003 \\
16.8311 & 13.8858
\end{array}\right]
$$

Finally, the degrees of consistency among the three alternatives were 0.9956, 0.9957, and 0.9955. In other words, the decision also satisfied the consensus threshold. The set of relative closeness values for the three alternatives was $\{0.5054,0.5093,0.5055\}$. Obviously, the investment selective performances of the three alternatives were quite approximate, which means it is hard to provide an optimal scheme for ship investment.

Comparatively, although the dual group decision fusion mechanism and the trapezoidal fuzzy group decision making method of both result in a high degree of consistency $(\beta=0.99)$, the dual group decision fusion featured greater consensus than the latter method. Moreover, as far as investment selection performance is concerned, the dual group decision method performed better on the whole; the performance values for more than two alternatives were larger than the corresponding values 
from the comparison method. In summary, the dual group decision fusion mechanism shows the best performance in the selection of dry cargo carriers for investment, and the best alternative was the multipurpose vessel.

According to the second comparison method or group decision by fuzzy TOPSIS, according to Step 1, the criteria weight is seen in Appendix B in Supplementary Materials. Then, the weighted normalized decision matrix, as seen in Appendix $C$ in the Supplementary Materials, was based on Step 2-Step 4. The FPIS of the three alternatives, and correspondingly the FNIS, was $\bar{S}_{2}$. Finally, the closeness coefficients of the three alternatives were $0.5536,0.5375$, and 0.5479 . The performances were also similar and did not help in distinguishing the alternatives.

As the market becomes increasingly subdivided, the segmentation of cargo can influence the selection of dry bulk carriers for investment. For example, ships containing green raw materials and equipment demonstrate better economic and environmental performance, while ships under the green supply chain aim at sustainable development and green competition. The differential investment selection of dry bulk carriers must result in differential performance. In terms of adapting to competition from other bulk carriers, multipurpose ship owners hope that future multipurpose ships will be more flexible and more convenient to load and unload. Recently, the multipurpose ship business began to analyze the development of the global multipurpose ship transport market and became particularly optimistic about the Chinese market. The change in cargo has led to an increase in the size of carriers, along with increases in the cargo holds; this is the trend in the development of multipurpose ships.

\section{Conclusions}

Ship investment selection is a classic MCDM issue. According to the classification of seaborne trade, dry bulk carriers occupy almost half of the territory. Apart from tankers, dry bulk carriers carry the largest amount of cargo. This paper studies three types of dry bulk carrier investment alternatives. Under the green supply chain, decision indices are constructed. The cognitive ability of multiple DMs is utilized to identify factors that influence the investment decision. Six influencing factors are chosen, and the corresponding indicators are constructed based on the sustainability requirement and green supply chain environment of dry cargo carriers.

A dual group decision fusion mechanism is proposed for evaluating the investment selection. The proposed method takes into account the scoring assessment and linguistic evaluation by integrating both of them into a unified evaluation term. A cloud model is also embedded into the proposed method to handle the ambiguity and randomness of DMs. The scoring assessment and linguistic evaluation complement each other, resulting in greater consistency and a higher level of performance. In addition, a consensus degree model and performance analysis ensure the validity and efficiency, respectively, of the decision. Finally, two group decision methods are used to evaluate the proposed method. Compared with other methods, the dual group decision fusion mechanism gives a more significant, reasonable, and accurate result. In a project involving the evaluation of dry bulk carriers for investment, the proposed method shows that the multipurpose vessel is the best alternative under the green supply chain.

Multi-functional ships not only have great flexibility and individuality in ship manufacturing and investment field, but also provide broad development space for sustainable development of enterprises, especially in energy-saving and environmentally-friendly ship systems. Practically, managers of ship enterprises, especially the dry bulk carriers' investment selection, are future-oriented competitors, as rational investors or investment managers need to respond to the long-term sustainable development of enterprises, which balances the immediate interests and long-term interests.

The policy implication guides the macroscopic concept, which needs to carry out policies and regulations. The constructed model of dry bulk carriers' investment selection is a shock to existing investment decision making on the evaluation of the decision making organization, procedure, and scheme. With the implementation of a sustainable ship investment selection model, it will also 
restructure the organization and redistribute the resources. The concept of sustainable green supply management is further strengthened in the process of investment selection for dry bulk carriers.

For future work, we would like to apply the dual fusing mechanism of group decision under green supply chain perspectives to investment structural adjustment of green capacity, complicated equipment, and major projects, as well as provide more effective policies and advice.

Supplementary Materials: The following are available online at http:/ / www.mdpi.com/2071-1050/10/12/4528/ s1.

Author Contributions: Conceptualization, S.Y., Y.S., and H.Y.; methodology, D.Y. and S.Y.; validation, D.Y. and S.Y.; formal analysis, S.Y. and Y.H.; investigation, S.Y. and H.Y.; resources, Y.S. and H.Y.; data curation, D.Y. and S.Y.; writing, original draft preparation, S.Y. and D.Y.; writing, review and editing, S.Y., D.Y., and B.G.; supervision, Y.S.; funding acquisition, Y.S.

Funding: This research was funded by the National Natural Science Foundation of China, Grant Numbers 71801061, 71101034, 71804084, and 71673119, the project of the Provincial Natural Science Foundation, Grant Number QC2016095, the project of the Provincial Postdoctoral Fund, Grant Number LBH-Z15047, the Humanities and social sciences fund of the Ministry of Education, Grant Number 18YJC630245, and the project of the Provincial Youth Science Fund, Grant Number JJ2016QN0645.

Acknowledgments: We would like to thank Benhai Guo and Yan Shen for their sincere suggestion.

Conflicts of Interest: The authors declare no conflict of interest.

\section{References}

1. Azimifard, A.; Moosavirad, S.H.; Ariafar, S. Selecting sustainable supplier countries for Iran's steel industry at three levels by using AHP and TOPSIS methods. Resour. Policy 2018, 57, 30-44. [CrossRef]

2. Fan, L.; Luo, M. Analyzing ship investment behaviour in liner shipping. Marit. Policy Manag. 2013, 40, 511-533. [CrossRef]

3. Thanki, S.; Thakkar, J. A quantitative framework for lean and green assessment of supply chain performance. Int. J. Product. Perform. Manag. 2018, 67, 366-400. [CrossRef]

4. Abbasi, M.; Nilsson, F. Themes and challenges in making supply chains environmentally sustainable. Supply Chain Manag. 2012, 17, 517-530. [CrossRef]

5. Sivakumar, R.; Kannan, D.; Murugesan, P. Green vendor evaluation and selection using AHP and Taguchi loss functions in production outsourcing in mining industry. Resour. Policy 2015, 46, 64-75. [CrossRef]

6. Rostamzadeh, R.; Govindan, K.; Esmaeili, A.; Sabaghi, M. Application of fuzzy VIKOR for evaluation of green supply chain management practices. Ecol. Indic. 2015, 49, 188-203. [CrossRef]

7. Sawik, B.; Faulin, J.; Pérez-Bernabeu, E. A multicriteria analysis for the green VRP: A case discussion for the distribution problem of a Spanish retailer. Transp. Res. Procedia 2017, 22, 305-313. [CrossRef]

8. Sawik, B.; Faulin, J.; Pérez-Bernabeu, E. Multi-criteria optimization for fleet size with environmental aspects. Transp. Res. Procedia 2017, 27, 61-68. [CrossRef]

9. Gallo, M. A fuel surcharge policy for reducing road traffic greenhouse gas emissions. Transp. Policy 2011, 18, 413-424. [CrossRef]

10. Ngo, V.D.; Frank, L.D.; Bigazzi, A.Y. Effects of new urban greenways on transportation energy use and greenhouse gas emissions: A longitudinal study from Vancouver, Canada. Transp. Res. Part D Transp. Environ. 2018, 62, 715-725. [CrossRef]

11. Steuera, R.E. Multiple criteria decision making combined with finance: A categorized bibliographic study. Eur. J. Oper. Res. 2003, 150, 496-515. [CrossRef]

12. Wallenius, J.; Dyer, J.S.; Fishburn, P.C.; Steuer, R.E.; Zionts, S.; Deb, K. Multiple criteria decision making, multiattribute utility theory: Recent accomplishments and what lies ahead. Manag. Sci. 2008, 54, 1336-1349. [CrossRef]

13. Li, J.; Rong, S.; Fang, L.; Yang, S.; Hou, B.; Wang, S.; Ma, W. Cognitive Computing and Multi-Objective Optimization; Science Press: Beijing, China, 2017.

14. Liu, P.; Zhang, X. A Novel Picture Fuzzy Linguistic Aggregation Operator and Its Application to Group Decision-making. Cogn. Comput. 2018, 10, 242-259. [CrossRef]

15. Sun, L.; Wang, Y. A multi-attribute fusion approach extending Dempster-Shafer theory for combinatorial-type evidences. Expert Syst. Appl. 2018, 96, 218-229. [CrossRef] 
16. Alcalde, C.; Burusco, A.; Fuentes-González, R.; Zubia, I. The use of linguistic variables and fuzzy propositions in the L L mathContainer Loading Mathjax-Fuzzy concept theory. Comput. Math. Appl. 2011, 62, 3111-3122. [CrossRef]

17. Bai, C.; Zhang, R.; Shen, S.; Huang, C.; Fan, X. Interval-valued probabilistic linguistic term sets in multi-criteria group decision making. Int. J. Intell. Syst. 2018, 33, 1301-1321. [CrossRef]

18. Zhang, B.; Liang, H.; Zhang, G. Reaching a consensus with minimum adjustment in MAGDM with hesitant fuzzy linguistic term sets. Inf. Fusion 2018, 42, 12-23. [CrossRef]

19. Gou, X.; Xu, Z. Novel basic operational laws for linguistic terms, hesitant fuzzy linguistic term sets and probabilistic linguistic term sets. Inf. Sci. 2016, 372, 407-427. [CrossRef]

20. Gou, X.; Liao, H.; Xu, Z.; Herrera, F. Double hierarchy hesitant fuzzy linguistic term set and MULTIMOORA method: A case of study to evaluate the implementation status of haze controlling measures. Inf. Fusion 2017, 38, 22-34. [CrossRef]

21. Wang, J.Q.; Kuang, J.J.; Wang, J.; Zhang, H.Y. An extended outranking approach to rough stochastic multi-criteria decision-making problems. Cogn. Comput. 2016, 8, 1144-1160. [CrossRef]

22. Pereira, J. The robust (minmax regret) assembly line worker assignment and balancing problem. Comput. Oper. Res. 2018, 93, 27-40. [CrossRef]

23. Jiang, B.; Narasimhan, C.; Turut, Ö. Anticipated regret and product innovation. Manag. Sci. 2016, 63, 4308-4323. [CrossRef]

24. Behret, H. Group decision making with intuitionistic fuzzy preference relations. Knowl. Based Syst. 2014, 70, 33-43. [CrossRef]

25. Liao, H.; Xu, Z.; Zeng, X.J.; Xu, D.L. An enhanced consensus reaching process in group decision making with intuitionistic fuzzy preference relations. Inf. Sci. 2016, 329, 274-286. [CrossRef]

26. Beierle, C. Management of uncertainty in Artificial Intelligence and databases. Int. J. Approx. Reason. 2017, 86, 24-25. [CrossRef]

27. Deyi, L.; Haijun, M.; Xuemei, S. Membership clouds and membership cloud generators. J. Comput. Res. Dev. 1995, 32, 15-20.

28. Shang, X.; Ma, P.; Chao, T. Performance Evaluation of Electromagnetic Railgun Exterior Ballistics Based on Cloud Model. IEEE Trans. Plasma Sci. 2017, 45, 1614-1621. [CrossRef]

29. Rodriguez, R.M.; Martinez, L.; Herrera, F. Hesitant fuzzy linguistic term sets for decision making. IEEE Trans. Fuzzy Syst. 2012, 20, 109-119. [CrossRef]

30. Cabrerizo, F.J.; Morente-Molinera, J.A.; Pedrycz, W.; Taghavi, A.; Herrera-Viedma, E. Granulating linguistic information in decision making under consensus and consistency. Expert Syst. Appl. 2018, 99, 83-92. [CrossRef]

31. Chen, C.T.; Lin, C.T.; Huang, S.F. A fuzzy approach for supplier evaluation and selection in supply chain management. Int. J. Prod. Econ. 2006, 102, 289-301. [CrossRef]

32. Sarkis, J. A strategic decision framework for green supply chain management. J. Clean. Prod. 2003, 11, 397-409. [CrossRef]

33. Zhu, Q.; Sarkis, J.; Lai, K.H. Green supply chain management innovation diffusion and its relationship to organizational improvement: An ecological modernization perspective. J. Eng. Technol. Manag. 2012, 29, 168-185. [CrossRef]

34. Zhu, Q.; Geng, Y.; Fujita, T.; Hashimoto, S. Green supply chain management in leading manufacturers: Case studies in Japanese large companies. Manag. Res. Rev. 2010, 33, 380-392. [CrossRef]

35. Yang, C.S.; Lu, C.S.; Haider, J.J.; Marlow, P.B. The effect of green supply chain management on green performance and firm competitiveness in the context of container shipping in Taiwan. Transp. Res. Part E Logist. Transp. Rev. 2013, 55, 55-73. [CrossRef]

36. Kehbila, A.G.; Ertel, J.; Brent, A.C. Strategic corporate environmental management within the South African automotive industry: Motivations, benefits, hurdles. Corp. Soc. Responsib. Environ. Manag. 2009, 16, 310-323. [CrossRef]

37. Chan, E.S.W. Implementing environmental management systems in small- and medium-sized hotels: Obstacles. J. Hosp. Tour. Res. 2011, 35, 3-23. [CrossRef]

38. Victor, A.; Pulidindi, I.N.; Gedanken, A. Assessment of holocellulose for the production of bioethanol by conserving Pinus radiata cones as renewable feedstock. J. Environ. Manag. 2015, 162, 215-220. [CrossRef] [PubMed] 
39. Zsidisin, G.A.; Siferd, S.P. Environmental purchasing: A framework for theory development. Eur. J. Purch. Supply Manag. 2001, 7, 61-73. [CrossRef]

40. Berling, P.; Eng-Larsson, F. Environmental implications of transport contract choice-capacity investment and pricing under volume and capacity contracts. Eur. J. Oper. Res. 2017, 261, 129-142. [CrossRef]

41. Shang, W.; Ha, A.Y.; Tong, S. Information sharing in a supply chain with a common retailer. Manag. Sci. 2015, 62, 245-263. [CrossRef]

42. Li, J.; Pan, S.Y.; Kim, H.; Linn, J.H.; Chiang, P.C. Building green supply chains in eco-industrial parks towards a green economy: Barriers and strategies. J. Environ. Manag. 2015, 162, 158-170. [CrossRef] [PubMed]

43. Zhu, Q.; Sarkis, J.; Lai, K.H. Initiatives and outcomes of green supply chain management implementation by Chinese manufacturers. J. Environ. Manag. 2007, 85, 179-189. [CrossRef] [PubMed]

44. Lai, K.H.; Lun, V.Y.; Wong, C.W.; Cheng, T. Green shipping practices in the shipping industry: Conceptualization, adoption, and implications. Resour. Conserv. Recycl. 2011, 55, 631-638. [CrossRef]

45. Keane, R.G.; McNatt, T.; Beach, J.E. Reducing Total Ownership Cost: Designing Robust Ship Structures. Nav. Eng. J. 2017, 129, 41-57.

46. Tseng, M.L.; Tan, R.R.; Siriban-Manalang, A.B. Sustainable consumption and production for Asia: Sustainability through green design and practice. J. Clean. Prod. 2013, 40, 1-5. [CrossRef]

47. Rao, P.; Holt, D. Do green supply chains lead to competitiveness and economic performance? Int. J. Oper. Prod. Manag. 2005, 25, 898-916. [CrossRef]

48. Khan, S.A.R.; Qianli, D. Impact of green supply chain management practices on firms' performance: An empirical study from the perspective of Pakistan. Environ. Sci. Pollut. Res. 2017, 24, 16829-16844. [CrossRef] [PubMed]

49. Yeh, W.C.; Chuang, M.C. Using multi-objective genetic algorithm for partner selection in green supply chain problems. Expert Syst. Appl. 2011, 38, 4244-4253. [CrossRef]

50. Tsai, C.Y. The impact of cost structure on supply chain cash flow risk. Int. J. Prod. Res. 2017, 55, 6624-6637. [CrossRef]

51. Awasthi, A.; Chauhan, S.S.; Goyal, S.K. A fuzzy multicriteria approach for evaluating environmental performance of suppliers. Int. J. Prod. Econ. 2010, 126, 370-378. [CrossRef]

52. Singh, A.; Teng, J.T. Enhancing supply chain outcomes through Information Technology and Trust. Comput. Hum. Behav. 2016, 54, 290-300. [CrossRef]

53. Chan, R.Y.; He, H.; Chan, H.K.; Wang, W.Y. Environmental orientation and corporate performance: The mediation mechanism of green supply chain management and moderating effect of competitive intensity. Ind. Mark. Manag. 2012, 41, 621-630. [CrossRef]

54. Papapostolou, N.C.; Pouliasis, P.K.; Kyriakou, I. Herd behavior in the drybulk market: An empirical analysis of the decision to invest in new and retire existing fleet capacity. Transp. Res. Part E Logist. Transp. Rev. 2017, 104, 36-51. [CrossRef]

55. Srivastava, S.K. Green supply-chain management: A state-of-the-art literature review. Int. J. Manag. Rev. 2007, 9, 53-80. [CrossRef]

56. Ma, P.; Zhang, C.; Hong, X.; Xu, H. Pricing decisions for substitutable products with green manufacturing in a competitive supply chain. J. Clean. Prod. 2018, 183, 618-640. [CrossRef]

57. Vachon, S.; Klassen, R.D. Environmental management and manufacturing performance: The role of collaboration in the supply chain. Int. J. Prod. Econ. 2008, 111, 299-315. [CrossRef]

58. Vachon, S.; Klassen, R.D. Extending green practices across the supply chain: The impact of upstream and downstream integration. Int. J. Oper. Prod. Manag. 2006, 26, 795-821. [CrossRef]

59. Zaheer, N.; Trkman, P. An information sharing theory perspective on willingness to share information in supply chains. Int. J. Logist. Manag. 2017, 28, 417-443. [CrossRef]

60. Laari, S.; Töyli, J.; Solakivi, T.; Ojala, L. Firm performance and customer-driven green supply chain management. J. Clean. Prod. 2016, 112, 1960-1970. [CrossRef]

61. Hsu, C.W.; Kuo, T.C.; Chen, S.H.; Hu, A.H. Using DEMATEL to develop a carbon management model of supplier selection in green supply chain management. J. Clean. Prod. 2013, 56, 164-172. [CrossRef]

62. Fritsch, J.; Poudineh, R. Gas-to-power market and investment incentive for enhancing generation capacity: An analysis of Ghana's electricity sector. Energy Policy 2016, 92, 92-101. [CrossRef]

63. Kahneman, D. Prospect theory: An analysis of decisions under risk. Econometrica 1979, 47, 278. [CrossRef] 
64. Dong, Y.; Luo, N.; Liang, H. Consensus building in multiperson decision making with heterogeneous preference representation structures: A perspective based on prospect theory. Appl. Soft Comput. 2015, 35, 898-910. [CrossRef]

65. Sindhu, S.; Nehra, V.; Luthra, S. Investigation of feasibility study of solar farms deployment using hybrid AHP-TOPSIS analysis: Case study of India. Renew. Sustain. Energy Rev. 2017, 73, 496-511. [CrossRef]

66. Zhang, Z.; Zhang, S. A novel approach to multi attribute group decision making based on trapezoidal interval type-2 fuzzy soft sets. Appl. Math. Model. 2013, 37, 4948-4971. [CrossRef]

67. Liang, C.; Zhao, S.; Zhang, J. Multi-criteria group decision making method based on generalized intuitionistic trapezoidal fuzzy prioritized aggregation operators. Int. J. Mach. Learn. Cybern. 2017, 8, 597-610. [CrossRef]

68. Ziemba, P. NEAT F-PROMETHEE-A New Fuzzy Multiple Criteria Decision Making Method Based on the Adjustment of Mapping Trapezoidal Fuzzy Numbers. Expert Syst. Appl. 2018, 110, 363-380. [CrossRef]

69. Aydin, N. A fuzzy-based multi-dimensional and multi-period service quality evaluation outline for rail transit systems. Transp. Policy 2017, 55, 87-98. [CrossRef]

(C) 2018 by the authors. Licensee MDPI, Basel, Switzerland. This article is an open access article distributed under the terms and conditions of the Creative Commons Attribution (CC BY) license (http:/ / creativecommons.org/licenses/by/4.0/). 